\title{
Recommendations for hemodynamic monitoring for critically ill children-expert consensus statement issued by the cardiovascular dynamics section of the European Society of Paediatric and Neonatal Intensive Care (ESPNIC)
}

Yogen Singh $^{1 *}$ D, Javier Urbano Villaescusa ${ }^{2}$, Eduardo M. da Cruz ${ }^{3}$, Shane M. Tibby ${ }^{4}$, Gabriella Bottari ${ }^{5}$, Rohit Saxena ${ }^{6}$, Marga Guillén ${ }^{7}$, Jesus Lopez Herce ${ }^{2}$, Matteo Di Nardo ${ }^{5}$, Corrado Cecchetti ${ }^{5}$, Joe Brierley ${ }^{6}$, Willem de Boode ${ }^{8}$ and Joris Lemson ${ }^{9}$

\begin{abstract}
Background: Cardiovascular instability is common in critically ill children. There is a scarcity of published highquality studies to develop meaningful evidence-based hemodynamic monitoring guidelines and hence, with the exception of management of shock, currently there are no published guidelines for hemodynamic monitoring in children. The European Society of Paediatric and Neonatal Intensive Care (ESPNIC) Cardiovascular Dynamics section aimed to provide expert consensus recommendations on hemodynamic monitoring in critically ill children.

Methods: Creation of a panel of experts in cardiovascular hemodynamic assessment and hemodynamic monitoring and review of relevant literature - a literature search was performed, and recommendations were developed through discussions managed following a Quaker-based consensus technique and evaluating appropriateness using a modified blind RAND/UCLA voting method. The AGREE statement was followed to prepare this document.

Results: Of 100 suggested recommendations across 12 subgroups concerning hemodynamic monitoring in critically ill children, 72 reached "strong agreement," 20 "weak agreement," and 2 had "no agreement." Six statements were considered as redundant after rephrasing of statements following the first round of voting. The agreed 72 recommendations were then coalesced into 36 detailing four key areas of hemodynamic monitoring in the main manuscript. Due to a lack of published evidence to develop evidence-based guidelines, most of the recommendations are based upon expert consensus.

(Continued on next page)
\end{abstract}

\footnotetext{
* Correspondence: Yogen.Singh@nhs.net

1 Department of Pediatrics - Neonatology and Pediatric Cardiology,

Cambridge University Hospitals and University of Cambridge School of

Clinical Medicine, Biomedical Campus, Hills Road, Cambridge CB2 OQQ, UK

Full list of author information is available at the end of the article
}

C C The Author(s). 2020 Open Access This article is licensed under a Creative Commons Attribution 4.0 International License, which permits use, sharing, adaptation, distribution and reproduction in any medium or format, as long as you give appropriate credit to the original author(s) and the source, provide a link to the Creative Commons licence, and indicate if changes were made. The images or other third party material in this article are included in the article's Creative Commons. licence, unless indicated otherwise in a credit line to the material. If material is not included in the article's Creative Commons licence and your intended use is not permitted by statutory regulation or exceeds the permitted use, you will need to obtain permission directly from the copyright holder. To view a copy of this licence, visit http://creativecommons.org/licenses/by/4.0/. The Creative Commons Public Domain Dedication waiver (http://creativecommons.org/publicdomain/zero/1.0/) applies to the data made available in this article, unless otherwise stated in a credit line to the data. 
(Continued from previous page)

Conclusions: These expert consensus-based recommendations may be used to guide clinical practice for hemodynamic monitoring in critically ill children, and they may serve as a basis for highlighting gaps in the knowledge base to guide further research in hemodynamic monitoring.

Keywords: Hemodynamic monitoring (HD), Paediatric intensive care unit (PICU), Children, Cardiovascular instability, Recommendations

\section{Introduction}

Circulatory shock is defined as a "life-threatening generalized the maldistribution of blood flow resulting in failure to deliver and/or utilize the adequate amount of oxygen, leading to tissue dysoxia" [1]. Cardiovascular instability with or without shock is common in children admitted to pediatric intensive care units. Over half of the children with hemodynamic instability in intensive care units have multiple-organ dysfunction and sepsis remains the leading cause [2]. Similarly, a multi-center international study (Sepsis Prevalence, Outcomes, and Therapies; SPROUT) reported that over two thirds of children with sepsis had multiorgan dysfunction, which was associated with a very high mortality. These data are similar to what has been described in the adult population [3]. However, there remains a paucity of data regarding the epidemiology of circulatory derangement in children and how best hemodynamic status can be evaluated or monitored in the pediatric intensive care units.

Multiple studies have established that early recognition and treatment of pediatric circulatory insufficiency or shock are crucial to improve survival. However, the optimal way to resuscitate children with circulatory failure is controversial. The exact order and quantity of fluids or vasoactive drug administration in the critically ill child with shock is supported by little evidence, although there are several consensus statements $[4,5]$.

Overzealous fluid resuscitation is detrimental to some children $[6,7]$. There is some consensus regarding the firstline treatment in patients with shock or significant hemodynamic instability, but debate remains concerning how much fluid should be administered, which type of vasoactive drug should be used, how to assess the hemodynamic changes, and ultimately what hemodynamic clinical goal should be targeted to guide optimal treatment.

Ideal hemodynamic monitoring should accurately determine the severity of circulatory derangement and illustrate the underlying pathophysiologic mechanism to enable the clinician to choose the most appropriate treatment and to guide the therapy $[7,8]$. Furthermore, hemodynamic monitoring can provide useful information about the circulatory condition in almost all types of life-threatening shock. This can be hemodynamic instability as a result of major surgery, cardiac failure, trauma, sepsis, or other causes of shock in children. The current guidelines mostly focus on early recognition and treatment but do not specify the type of monitoring technology that can or should be used under various circumstances. There are still no published evidence-based or even consensus guidelines specifically for hemodynamic monitoring in neonates and children. However, there is a wide range of devices and techniques available to evaluate the hemodynamic status and an increasing number of these methods have become available for use in children. In the annual meeting of the European Society of Paediatric and Neonatal Intensive Care (ESPNIC) in October 2016, members of the Cardiovascular Dynamics Section were tasked to develop evidence-based guidelines if at all possible, or an expert consensus statement on the hemodynamic monitoring specifically for use in children.

\section{Methods}

A steering committee (SC) of three lead authors, one pediatric intensivist/anesthesiologist (JL), one neonatologist/pediatric cardiologist (YS), and one pediatric intensivist (JU), identified nine expert panel members who significantly contributed with publications in hemodynamic monitoring or cardiovascular status assessment in children in the last 10 years, similarly to what had been done with previous ESPNIC guidelines [9-11]. Further, the three selection criteria for inclusion as panel member were (1) must be clinicians working in a pediatric or neonatal intensive care, (2) needed to have experience with some form of HD monitoring, and (3) should have published in peerreviewed journals concerning the topic. Panelists' selection was performed prior to the literature search, and for logistic reasons, the number of participants was limited to a maximum of 12. All invited experts agreed to participate.

The working group had face-to-face meetings during the ESPNIC conference in Lisbon 2017 and the European Academy of Paediatric Societies (EAPS) conference in Paris in 2018 and unanimously agreed to provide recommendations from full-term infants over 37 weeks of gestation and over 4 weeks of postnatal age (lower limit) to 18 years old (upper limit), in order not to overlap with preterm-neonatal and adult guidelines. The panel subdivided hemodynamic monitoring into 12 subgroups: arterial blood pressure, central venous pressure, pulmonary artery catheter, cardiac output, transpulmonary thermodilution, central venous oxygen saturation measurement, lactate levels, clinical signs, near-infrared spectroscopy, 
fluid responsiveness, microcirculation, and role of ultrasonography.

Panel members were assigned in pairs to one of the subgroups, and each subgroup was coordinated by one of the steering committee members. The tasks of each subgroup consisted of performing a thorough review of the literature, writing a short description of the parameter/method, the technical background and physiological basis, writing a short overview of the reliability of the method if applicable, establishing, when possible, normal or target values, estimating the clinical value of the method, or parameter in relation to the patient categories mentioned. Because of the hemodynamic knowledgeable background of the panel members, these documents served as an overview to provide the entire panel with recent collective knowledge. The documents were not intended as a structured systemic review of the specific technology or method. Also, given that there is only low-quality data available in many aspects of hemodynamic monitoring in children, and that the focus of this work was to reach a consensus within the panel of experts, the working group decided not to use the GRADE system to evaluate the literature [12]. The definition of hemodynamic instability was not ill-defined but intended as a clinical description reflecting the child in need for fluid resuscitation or vasoactive drugs.

Finally, 3 types of recommendations were formulated as follows: (1) recommendations considering the reliability of methods, but only if applicable; (2) recommendations considering normal or target values, but only if applicable; and (3) recommendations considering clinical use in relation to specific patient groups.

The setup and some proposed recommendations were discussed in a face-to-face meeting during the European Academy of Pediatric Societies (EAPS) in Paris, France (October 2018). In May 2019, an anonymous electronic voting system (Survey Monkey ${ }^{\circ}$, San Mateo, USA) was used to vote on all recommendations by each panel member including the SC. Each panel member was given access to all the work from other subgroups with text, results, and full-text publications in order to vote with all available evidence. Panel members scored all the recommendations individually from 1 (complete disagreement) to 9 (complete agreement). The median score was calculated after eliminating one lowest and one highest value. Recommendations were labeled "strong agreement" (median 7-9 and with no individual score $<7$ ), "equipoise" (median 4-6), or "disagreement" (median 1-3).

All recommendations that reached "strong agreement" in the first voting round according to the above scoring system acquired the strong agreement label. All recommendations that reached "equipoise" or "disagreement" in the first voting round were discussed and rephrased in the panel meeting during the ESPNIC conference in Salzburg, Austria (June 2019). The revised recommendations underwent the same voting process as in the first round. The revised recommendations retaining "strong agreement" after the second electronic voting were labeled as "weak agreement." All other revised recommendations were classified as "no agreement." Guidelines have been prepared according to the international Appraisal of Guidelines, Research and Evaluation (AGREE) [13].

\section{Results}

One hundred recommendations were drafted and voted by the panel for the level of agreement. Seventy-two recommendations reached "strong agreement" after the first round. The remaining 28 recommendations, where no "strong agreement" was reached, were discussed in a faceto-face panel meeting during the ESPNIC conference in Salzburg, Austria (June 2019): 21 were rephrased for 2nd round of voting, one was designated as "no agreement," and panel proposed deleting 6 recommendations as they were thought to be redundant after discussing all other recommendations (Fig. 1).

Finally, of the total 94 recommendations, 72 reached "strong agreement," 20 "weak agreement," and on 2 proposed recommendations "no agreement" was reached as summarized in "Supplementary file - Table 1."

\section{Discussion and evidence for the recommendations}

The details of technique, methods, reliability, search for published evidence, and references are provided in the online supplement (https://doi.org/10.1186/s13054-02003326-2). The commonly used parameters for hemodynamic monitoring in critically ill children are measurements of the blood pressure, central venous pressure (CVP), central venous oxygen saturation, cardiac output, serum lactate, pulmonary artery catheter, transpulmonary dilution, clinical signs, near-infrared spectroscopy, fluid responsiveness, microcirculation, and role of ultrasonography A brief summary of the evidence related to each sub-section has been summarized below.

\section{Clinical signs}

Pediatric resuscitation courses (such as ETAT WHO, APLS) teach initial assessment of the shocked child well. Most caregivers will be familiar with the clinical signs and symptoms that help assess the hemodynamic status in children, including heart rate (HR), blood pressure, respiratory rate (RR), state of consciousness, diuresis, core and peripheral temperature, capillary refill time, and peripheral perfusion. Some of these parameters are age-dependent, and some can be altered by ambient temperature, pain, anxiety, and many other factors. The mission of the primary resuscitation team is to identify the shocked child in need for urgent intervention and treatment, usually with fluids and then inotropes or vasopressors in some combination. 


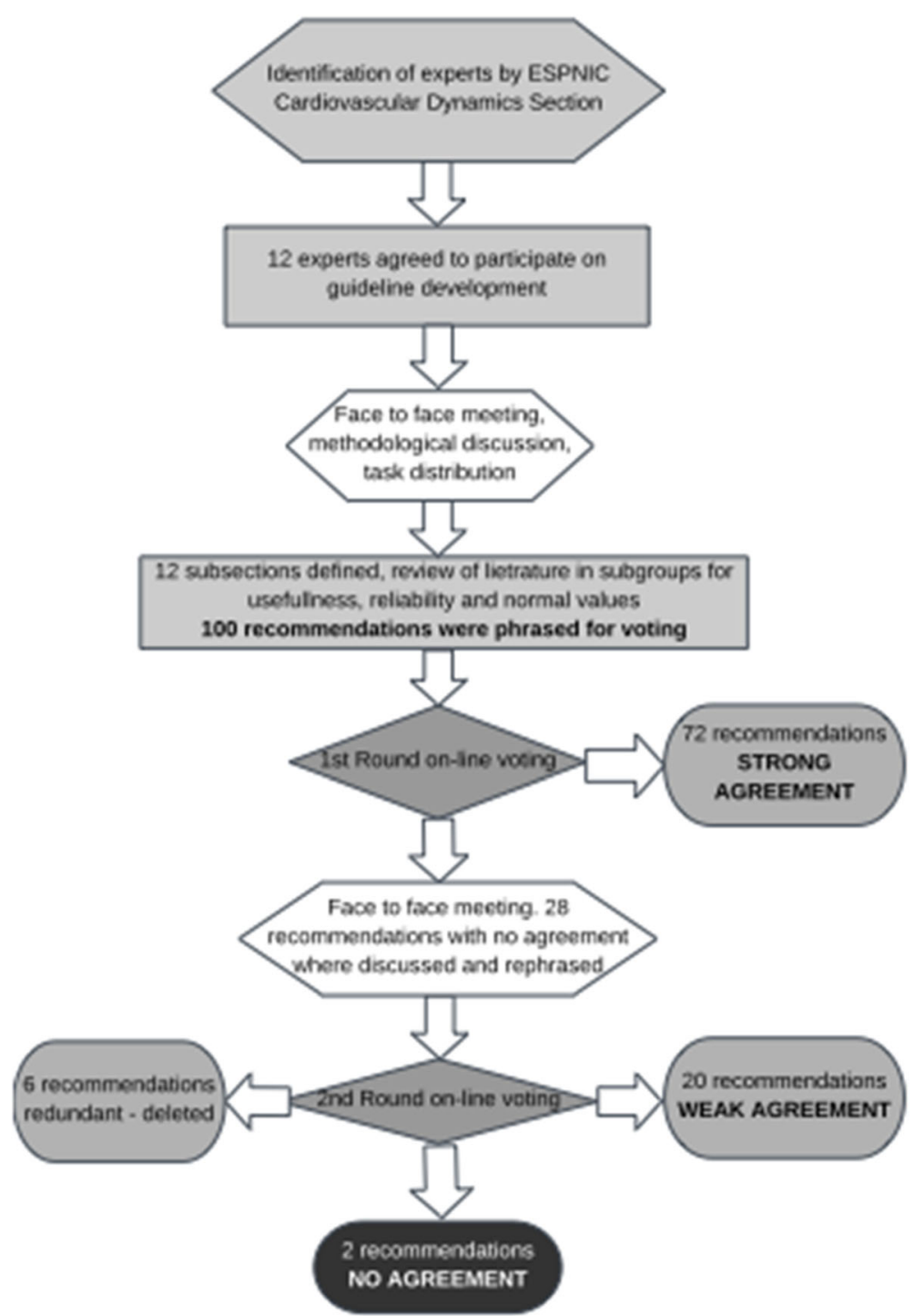

Fig. 1 Flow chart of the methodology used in consensus development

All recommendations reached a high level of agreement, both in identifying children in need for treatment and in the limited value of clinical signs to guide hemodynamic treatment. There is a significant variability in clinicians' abilities to assess hemodynamic clinical parameters at the bedside. Early signs of hemodynamic decompensation may be subtle and can be easily missed by the clinicians [14]. For these reasons, the frequent and trend evaluation of clinical signs are more important than a single specific determination. A combination of vital signs can be more useful to evaluate hemodynamic state than individual parameters [15].

Disappointingly, there is no good correlation between clinical assessment and invasive hemodynamic parameters, which only indicates that clinical parameters and invasive parameters do not measure the same compartment [16].
Hence, in hemodynamically unstable patients apart from frequent meticulous assessment, monitoring trends of several measurable clinical, biochemical, and monitoring parameters should be used to guide the therapy timely and accurately (Table 1).

\section{Arterial blood pressure}

Blood pressure (BP) measurement is one of the most commonly used hemodynamic parameters for diagnostic and therapeutic decisions in critically ill children, not least due to ease of utilization and, if invasive, the additional benefit of arterial blood sampling, as well as continuous data sampling. Both a low and a high BP on admission are related to an increased mortality [17]. Accurate measurement of $\mathrm{BP}$ is considered essential for the diagnosis and treatment of hypertension as well as of hypotension, including 
Table 1 Recommendations on use of clinical examination and blood pressure measurement in hemodynamic monitoring in critically ill children

\begin{tabular}{|c|c|c|}
\hline Sr No & Recommendation & Level of agreement \\
\hline \multicolumn{3}{|c|}{ Clinical signs } \\
\hline 1. & $\begin{array}{l}\text { There is no single clinical parameter that allows to evaluate the global hemodynamic status in children } \\
\text { and, therefore, we recommend to analyze several parameters and make frequent assessments. }\end{array}$ & Strong agreement \\
\hline 2. & $\begin{array}{l}\text { We recommend to perform a clinical assessment as the initial evaluation in all patients for the detection } \\
\text { of hemodynamic alterations and to evaluate clinical signs periodically together with hemodynamic } \\
\text { monitoring parameters in unstable patients. }\end{array}$ & Strong agreement \\
\hline 3. & $\begin{array}{l}\text { We do not recommend to titrate hemodynamic therapy or fluid loading solely based upon clinical signs } \\
\text { or a reduced urine output alone in unstable patients with the exception of the initial resuscitation phase. }\end{array}$ & Strong agreement \\
\hline \multicolumn{3}{|c|}{ Arterial blood pressure } \\
\hline 4. & $\begin{array}{l}\text { We recommend the use of intra-arterial blood pressure (IBP) over oscillometric blood pressure (OBP) } \\
\text { measurement when a reliable blood pressure (BP) measurement is of importance or when fast changes } \\
\text { in blood pressure need to be detected. }\end{array}$ & Strong agreement \\
\hline 5. & $\begin{array}{l}\text { In children over } 12 \text { years of age we recommend a target blood pressure of } \geq 65 \mathrm{mmHg} \text { MAP (according } \\
\text { to adults surviving sepsis guidelines) unless in children known to have prior hypertension. }\end{array}$ & Strong agreement \\
\hline 6. & $\begin{array}{l}\text { We recommend not to use BP as the only therapeutic target in unstable children. The hemodynamic } \\
\text { state should be evaluated integrating several clinical and hemodynamic parameters. }\end{array}$ & Strong agreement \\
\hline 7. & $\begin{array}{l}\text { We recommend IBP monitoring in children in shock not responsive to initial fluid therapy or requiring } \\
\text { vasopressor treatment, and hypertensive emergencies to control the effect of continuous invasive } \\
\text { hypotensive drugs. }\end{array}$ & Strong agreement \\
\hline
\end{tabular}

various categories of hemodynamic shock $[18,19]$. BP can be measured invasively but also by using several less reliable non-invasive methods [20].

The committee strongly agreed on the use of intraarterial blood pressure (IBP) over oscillometric blood pressure (OBP) measurement when there is a need for reliable BP measurement in children with shock not responding to initial fluid therapy or requiring inotropes or vasoactive medication; in patients with intracranial hypertension and intracranial pressure monitoring to measure cerebral perfusion pressure; during major surgery and in children with malignant hypertension or other hypertensive emergencies and to monitor the effect of continuous intravenous vasoactive medications or inotropes. However, the clinical value of BP in guiding hemodynamic therapy was not appreciated equally among the panel members. Nevertheless, there was strong agreement that BP should not be used as the only therapeutic target in unstable children, so the hemodynamic state should be evaluated integrating BP with several clinical and additional hemodynamic parameters [21].

Optimal values for BP in healthy and critically ill children, including therapeutic thresholds, should be related to the clinical condition, age, sex, and body size [20-25]. There was only weak agreement concerning BP values in children under 12 years of age. In children over 12 years of age generally, we strongly recommend a target mean arterial pressure (MAP) of $\geq 65 \mathrm{mmHg}$, although in specific situations, the targeted BP may be higher such as when managing raised intracranial pressure.

\section{Central venous pressure (CVP)}

The committee shared a strong common opinion regarding CVP. CVP should be measured as accurately as possible and be evaluated only as part of multi-modal hemodynamic monitoring to assess the intravascular volume and cardiac function [26, 27]. Isolated CVP measurement is of limited value but trends of CVP, both the value and the wave morphology, or change in CVP in response to fluid or vasoactive therapy may provide useful information about the overall hemodynamic status and cardiovascular physiology in critically ill children. Specifically, a rise or high levels of CVP should be avoided [28]. The committee agreed that CVP is not of great value in the initial treatment of critically ill children, but it can deliver important additional information in children with shock refractory to initial hemodynamic treatment; however, the use of CVP requires a good understanding of its limitations and pathophysiology of underlying disease process. For example, CVP should not be used as a sole parameter to guide fluid therapy [29-32].

\section{Central venous oxygen saturation measurement}

Central venous oxygen saturation $\left(\mathrm{ScvO}_{2}\right)$ approximates but does not equal mixed oxygen saturation $(\mathrm{SmvO} 2)$. The normal ranges for ScvO2 and $\mathrm{SmvO} 2$ are $70-80 \%$ and 60 $70 \%$, respectively, in the setting of a normal aortic saturation $[33,34]$. Trends between $\mathrm{ScvO} 2$ and SmvO2 are often interchangeable, although $\mathrm{SmvO} 2$ values are generally around 7-10\% lower than $\mathrm{ScvO} 2$. A low $\mathrm{ScvO}_{2}$ typically indicates a mismatch between oxygen supply and utilization. Conversely, a normal, or high $\mathrm{ScvO}_{2}$ value, does not necessarily signify supply-demand adequacy, as tissue dysoxia 
(which may occur in sepsis) may cause an artificial elevation (or normalization) of $\mathrm{ScvO}_{2}$. Lastly, $\mathrm{ScrO} 2$ in isolation cannot be considered a surrogate of cardiac index/cardiac output [35]. However, there is some evidence that resuscitation in sepsis might be more beneficial when $\mathrm{ScrO}_{2}$ is incorporated in the treatment strategy [36].

The committee agreed that $\mathrm{ScvO}_{2}$ is an important parameter in unstable patients not responding to the first treatment and that its trend is helpful in hemodynamic management. However, we recommend that hemodynamic therapy should not be targeted solely based upon $\mathrm{ScvO}_{2}$ levels (Table 2).

\section{Volume resuscitation and fluid responsiveness}

Volume resuscitation is one of the most commonly used therapeutic options. Nevertheless, excessive fluid administration may impair tissue perfusion even further by promoting edema and third-space fluid accumulation $[6,7$, 37]. A rise in cardiac output (or stroke volume) as a result of volume resuscitation is called fluid responsiveness. To prevent unnecessary fluid administration, it could be beneficial to predict fluid responsiveness before the fluids are delivered. Unfortunately, there is no clear, simple, and proven method to predict fluid responsiveness in children. Static measures, mostly CVP, are not appropriate to test fluid responsiveness [29, 31]. The published evidence suggests that respiratory variation in aortic blood flow peak velocity $\{(\Delta \mathrm{VPeak} /$ velocity time integral $(\mathrm{VTI})\}$ is the most reliable indicator of fluid responsiveness, but only in ventilated children that fulfil various criteria [38]. Other dynamic methods, like passive leg raising test and liver pressure, have not been adequately assessed in children of all ages [39].

Due to the lack of simple bedside, available methods to determine fluid responsiveness and the risk of fluid overload with aggressive approach, the committee recommended the following: recurrent smaller fluid boluses (maximal $5-10 \mathrm{ml} / \mathrm{kg}$ ) in a short-time interval in patients with hemodynamic instability while tracking changes in cardiac output, blood pressure, and CVP to confirm or

Table 2 Recommendations on use of measurement of $\mathrm{CVP}_{1} \mathrm{SCVO}_{2}$, and prediction of fluid responsiveness in hemodynamic monitoring in critically ill children

\begin{tabular}{|c|c|c|}
\hline Sr No & Recommendation & Level of agreement \\
\hline \multicolumn{3}{|c|}{ Central venous pressure } \\
\hline 1. & $\begin{array}{l}\text { We recommend to place the tip of a central venous catheter at the junction of the superior caval } \\
\text { vein }(\mathrm{SCV}) \text { and the right atrium to obtain an optimal central venous pressure (CVP) measurement } \\
\text { or } \mathrm{ScvO}_{2} \text { sample. }\end{array}$ & Strong agreement \\
\hline 2. & We recommend to measure CVP in all unstable patients refractory to initial hemodynamic treatment. & Strong agreement \\
\hline 3. & $\begin{array}{l}\text { We recommend against the use of CVP to predict fluid responsiveness; Fluid loading should not } \\
\text { be started solely based upon a low CVP. }\end{array}$ & Strong agreement \\
\hline 4. & $\begin{array}{l}\text { An isolated CVP measurement is of limited value in clinical practice. However, trends in CVP may } \\
\text { provide important information regarding changes in cardiovascular pathophysiology such as evolving } \\
\text { right heart failure and an abrupt elevation in CVP upon fluid administration should raise suspicion } \\
\text { of significant cardiac dysfunction. }\end{array}$ & Strong agreement \\
\hline \multicolumn{3}{|c|}{ Central venous oxygen saturation measurement } \\
\hline 5. & $\begin{array}{l}\text { We recommend to measure central venous oxygen saturation }\left(\mathrm{ScvO}_{2}\right) \text { in unstable patients not } \\
\text { responding to the initial treatment. } \mathrm{ScvO}_{2}<65 \% \text { suggest a possible hemodynamic alteration; } \\
\text { however, in sepsis, a normal or high } \mathrm{ScvO}_{2} \text { may reflect mitochondrial dysfunction and mask } \\
\text { hemodynamic alterations. }\end{array}$ & Strong agreement \\
\hline 6. & $\mathrm{ScvO}_{2}$ is not an adequate marker of cardiac index (CI). & Strong agreement \\
\hline 7. & We recommend against targeting hemodynamic therapy solely based upon $\mathrm{ScvO}_{2}$. & Strong agreement \\
\hline \multicolumn{3}{|c|}{ Volume resuscitation and fluid responsiveness } \\
\hline 8. & $\begin{array}{l}\text { We recommend to observe the patient's clinical situation, physical exam, and various perfusion } \\
\text { indicators suggesting an inadequate CO (or oxygen transport) caused by hypovolemia before } \\
\text { considering fluid loading. }\end{array}$ & Strong agreement \\
\hline 9. & $\begin{array}{l}\text { In delivering a bolus of fluid, we recommend to administer a small bolus of fluid in a short time } \\
\text { period while tracking changes in cardiac output, blood pressure and CVP, and when possible or } \\
\text { available, to confirm fluid responsiveness before commencing fluid loading therapy. }\end{array}$ & Strong agreement \\
\hline 10. & We recommend alternative therapeutic strategies for hypotension management in fluid non-responders. ${ }^{* *}$ & Strong agreement \\
\hline 11. & $\begin{array}{l}\text { We recommend to withhold fluid therapy in patients with an increasing CVP and no significant } \\
\text { increase in blood pressure or cardiac output as a result of previous fluid therapy. }\end{array}$ & Strong agreement \\
\hline 12. & $\begin{array}{l}\text { We recommend fluid therapy (with boluses } 5-10 \mathrm{ml} / \mathrm{kg} \text { ) as part of early resuscitation in unstable } \\
\text { patients guided by the effect on blood pressure and/or cardiac output. }\end{array}$ & Strong agreement \\
\hline
\end{tabular}


assess fluid responsiveness. Furthermore, we strongly agreed to recommend withholding fluid therapy in patients with an increasing CVP and no significant increase in blood pressure or cardiac output as a result of previous fluid therapy. No specific recommendations regarding estimating fluid responsiveness can be made in patients with raised intracranial pressure or extracorporeal life support (ECLS).

\section{Echocardiography/ultrasonography}

Cardiac ultrasound or functional echocardiography is noninvasive and easily available at the bedside in the intensive care setting, and it allows rapid evaluation of hemodynamic status in real time. It can be used to assess cardiac function and preload, to estimate cardiac output and fluid responsiveness, to measure pulmonary artery systolic pressure and serial assessment, and allows to evaluate response to therapy $[10,40]$. Hence, it can be used, as an adjunct to other parameters, in children with hemodynamic instability to gain additional information required for making accurate clinical decisions such as myocardial failure, pulmonary hypertension, or cardiac tamponade [10]. It can help in understanding the pathophysiology of shock in children, and it can help in selecting timely, targeted specific, and right intervention [10, 41, 42].

The committee strongly recommended the use of cardiac ultrasound for hemodynamic evaluation of infants and children with hemodynamic instability. Since cardiac ultrasonography does not provide continuous measurements and is limited by a wide intra- and inter-observer variability $[40,43]$, we strongly recommend using serial assessments. However, we do not consider cardiac ultrasound as a tool for the routine hemodynamic monitoring in the intensive care setting (Table 3).

Table 3 Recommendations on the use of cardiac ultrasound and other methods to estimate cardiac output for hemodynamic monitoring in critically ill children

\begin{tabular}{|c|c|c|}
\hline Sr No & Recommendation & Level of agreemen \\
\hline \multicolumn{3}{|c|}{ Echocardiography/cardiac ultrasound } \\
\hline 1. & $\begin{array}{l}\text { We recommend to use cardiac ultrasound as an adjunct to gain additional information } \\
\text { required for making accurate clinical decisions in infants and children with hemodynamic } \\
\text { instability but not as a tool for routine hemodynamic monitoring in intensive care setting. }\end{array}$ & Strong agreement \\
\hline 2. & $\begin{array}{l}\text { Cardiac ultrasound can help in diagnosing pulmonary hypertension and assessing severity } \\
\text { of pulmonary hypertension, and in detecting cardiac tamponade. }\end{array}$ & Strong agreement \\
\hline 3. & $\begin{array}{l}\text { We recommend monitoring of pulmonary artery pressure (PAP) using ultrasound with } \\
\text { refractory shock states to exclude pulmonary hypertension. Cardiac ultrasound may help } \\
\text { in identifying underlying pathophysiology of shock and choosing the right intervention } \\
\text { based upon deranged hemodynamic physiology (preload, afterload, or cardiac function). }\end{array}$ & Strong agreement \\
\hline 4. & $\begin{array}{l}\text { Cardiac ultrasound may help in assessing fluid responsiveness and we recommend using } \\
\text { velocity time integral (VTI) across aortic valve for assessing fluid responsiveness rather than } \\
\text { inferior vena cava collapsibility in mechanically ventilated infants and children. }\end{array}$ & Strong agreement \\
\hline 5. & $\begin{array}{l}\text { We recommend using serial longitudinal assessments to assess response to therapy in } \\
\text { patients with significant hemodynamic instability. }\end{array}$ & Strong agreement \\
\hline
\end{tabular}

\section{Cardiac output measurement and transpulmonary indicator dilution}

6. We recommend to use ultrasound/Doppler-based methods of estimating CO in stable patients, for the initial assessment of unstable patients and to decide if a more invasive method is

Strong agreement required. When reliable absolute measurements of $\mathrm{CO}$ are deemed necessary, thermodilution (TPD) is the method of first choice.

7. In patients with a refractory shock when an accurate measurement of $\mathrm{CO}$ is needed, we recommend to use transpulmonary thermodilution (TPTD) or semi-invasive transpulmonary ultrasound dilution (TPUD).

8. We recommend to use invasive (and if possible continuous) CO monitoring in unstable post-operative patients after major (cardiothoracic) surgery, multiple trauma injuries or burns or patients with complex cardiopulmonary interactions.

9. We recommend against targeting fluid therapy based upon blood volumes measured with TPD or targeting hemodynamic therapy based upon lung water measurement to assess pulmonary edema in critically ill children.

10. Because of their intermittent measurement technique, TPD methods are not suitable for the detection of fast changes in CO unless used in conjunction with continuous trend monitoring using pulse contour analysis, calibrated by transpulmonary indicator dilution technology.

Weak agreement

Strong agreement

Strong agreement

Strong agreement

\section{Pulmonary artery pressure} after lung transplant using a surgically inserted catheter can be helpful 


\section{Cardiac output monitoring and transpulmonary indicator dilution}

Cardiac output $(\mathrm{CO})$ is the product of heart rate and stroke volume. Stroke volume depends on preload, contractility, and afterload. The physical examination and simple commonly used hemodynamic parameters are the surrogate markers of cardiovascular well-being, but they do not provide a direct assessment of the cardiovascular hemodynamic status of the patient and clinical estimation of cardiac output has showed to be mostly inaccurate [14]. Hence, there seems to be a need of advanced hemodynamic monitoring to titrate therapies specifically when volume expansion or vasoactive drugs are delivered in order to improve cardiac output or systemic vascular resistance $[44,45]$. In patients with refractory shock, when an effective and accurate measurement of $\mathrm{CO}$ is needed, the following methods may be used depending upon available resources and expertise: measurement of CO using transthoracic ultrasound (echocardiography) and transpulmonary dilution (TPD) [44-46]. Ultrasonography is non-invasive, easily available, and can provide a fairly accurate and serial estimation of cardiac output at the bedside to monitor the initial response to therapy $[40,47]$. However, it requires specific skills and it is operator-dependent. Despite being the most reliable clinical method to measure cardiac output, the application of TPD in the clinical practice may be challenging because of resources, technical difficulties, or lack of expertise. It is invasive and not suited to emergency resuscitation. Only two methods are available in children below $40 \mathrm{~kg}$ : transpulmonary thermodilution (TPTD) by PiCCO (Pulsion Medical Systems, Germany) and transpulmonary ultrasound dilution (TPUD) by $\mathrm{CO}$ status (Transonic, USA) [44-46, 48]. Neither is in frequent use in ICU due to their intricate set-up, and particularly for PICCO, the risk to children's vessels from relatively large femoral arterial catheter required. Moreover, because of their intermittent measurement technique, TPD methods are not suitable for the detection of rapid, frequent, and changes in hemodynamic status, as required in some critically ill children.

In the clinical practice, we recommend to use cardiac output ultrasound/Doppler methods for estimating $\mathrm{CO}$ in stable patients and the initial assessment of unstable patients. The committee did not reach to a strong agreement on the methods to estimate $\mathrm{CO}$ in children with refractory shock needing escalation of treatment and hemodynamic monitoring. There was a strong agreement that TPD methods are the most reliable but whether their use should be advised in situations needing escalation only reached a weak agreement. TPD methods also measure blood volumes and lung water, but the committee recommended against using these parameters for targeting hemodynamic goals. Measuring $\mathrm{CO}$ using PAC is not recommended.
Cardiac output can also be estimated at the bedside using other non-invasive methods like bioimpedance and bioreactance, pulse contour, and Doppler. Validation of these methods in critically ill children is sparse, and these methods are therefore not consensually viewed as accurate enough to estimate absolute values of $\mathrm{CO}$ in the intensive care setting in children [49]. However, they might provide a trend over time. In general, the committee strongly agreed that at the current time no recommendations regarding these methods can be given due to the limited experiences in critically ill children.

\section{Pulmonary artery pressure (PAP)}

The pulmonary artery catheter (PAC) can provide continuous measurement of right atrial, PAP, measurement of $\mathrm{CO}$, and pulmonary arterial occlusion pressure (wedge pressure). However, because of invasiveness and size, it is not used or recommended in intensive care clinical practice in children [50]. Similarly, left atrial pressure can be measured using surgically inserted left atrial catheters (LAC) $[51,52]$. Still, alternative less invasive techniques are being used in children to estimate left atrial pressure in unstable patients and LAC or PAC are rarely used in today's intensive care clinical practice $[53,54]$.

Because of the above, the committee recommends not to use a PAC in children to measure cardiac output or PAP in the ICU. Instead, transthoracic ultrasound echocardiography can be easily used to estimate PAP at the bedside non-invasively and it can provide serial assessment to monitor the response to therapy or disease process (as above). However, it should not be used to estimate PAP in patients with right ventricular (RV) failure [55]. For precise measurement of PAP, we recommend using the PAC only at the cardiac catheterization laboratory.

\section{Lactate measurement}

Determination of blood lactate concentration is a cheap, fast, and easy bedside parameter that has demonstrated utility to predict the outcome or to trigger the need to intensify medical treatment [56]. The committee showed some variation in their approach to the use of lactate in children since 5 out of 10 recommendations needed a revision.

In critically ill patients or children with shock, early and serial lactate blood sampling from a reliable site such as a central venous or arterial indwelling catheter is recommended, though peripheral venous sampling with tourniquet time $<60 \mathrm{~s}$ is possible [57]. This is specifically recommended when the initial capillary lactate value is > $3.0 \mathrm{mmol} / \mathrm{L}$ [57-59]. Studies report an association between failure to normalize lactate levels to a certain threshold $(3.0 \pm 1.0 \mathrm{mmol} / \mathrm{L})$ during the first 12 to $24 \mathrm{~h}$ of ICU admission, and adverse outcomes regardless of the reason for ICU admission [60, 61]. Experts could not agree on the use of lactate as part of a goal-directed approach and only 
weakly agreed on the approach to a persistent high lactate level. In the latter, lactate levels should always be used in conjunction with other clinical indicators of poor systemic perfusion and monitoring parameters. Persistently elevated lactate levels may reflect other mechanisms rather than those derived from poor tissue perfusion in shock and instead reflect aerobic glycolytic mechanisms including catecholamine administration or endogenous release [62] (Table 4).

\section{Near-infrared spectroscopy}

Near-infrared spectroscopy (NIRS) is a non-invasive, bedside technique to estimate regional capillary-venous hemoglobin saturation ( $\mathrm{rSO} 2)$. The mean baseline cerebral $\mathrm{rSO}_{2}$ is $>70 \%$ in healthy children. Infants and children with cyanotic heart disease may have a cerebral $\mathrm{rSO}_{2}$ between 46-57\% [63-67]. Moreover, practitioners should be mindful about a considerable variability in NIRS values between commercially available devices. It has been observed that values measured in both monitors INVOS 5100- $\mathrm{C}^{\bullet}$ (Medtronic; Boulder, CO, USA) and Foresight Elite $^{\bullet}$ monitor (CAS Medical Systems; Branford, CN, USA) are not interchangeable [68]. Although NIRS is mainly used to measure $\mathrm{rSO} 2$ in the brain, there are also reports of its use on other organs. In a study by Dabal et al. [69], it appears that renal NIRS and inferior vena cava desaturations precede $\mathrm{rScO} 2$ changes in the prediction of serious cardiovascular adverse events in patients after stage 1 Norwood palliation. Trend in NIRS values may provide valuable physiological information in children with hemodynamic instability although clear (cutoff) values and evidence of benefit are lacking.

The committee strived to define recommendations with regard to this subject and 6 out of 7 recommendations had to be redefined. As a result, the only strong recommendation was to advise against routine use of NIRS in all children with hemodynamic instability. Moreover, the committee agreed not to make recommendations regarding the use of NIRS while treating children in shock, post-cardiac arrest, post traumatic brain injury, and infants with hypoxic-ischemic encephalopathy. Lastly, there was no agreement on the clinical usefulness of a decline of cerebral $\mathrm{rSO} 2$ under $40-50 \%$ or a change in baseline of more than $20 \%$ [70].

\section{Microcirculation}

Microcirculatory assessment by videomicroscopy using side-stream or incident dark field is expensive and not widely available. Currently, it does not allow for assessment of rapid circulatory changes during resuscitation [71]. No studies have defined the normal values of microcirculation in children outside the neonatal period but do report that vascular density seems to decrease with age [72]. So far, published studies have not defined target values of microcirculatory parameters in critically ill children [72-77]. At this point in time, the committee recommends its use only for research purposes.

The committee also states that many routinely used parameters like capillary refill, peripheral temperature,

Table 4 Recommendations on use of serum lactate, near infrared spectroscopy (NIRS), and microcirculation assessment for hemodynamic monitoring in critically ill children

\begin{tabular}{|c|c|c|}
\hline Sr No & Recommendation & Level of agreement \\
\hline \multicolumn{3}{|c|}{ Serum lactate measurement } \\
\hline 1. & $\begin{array}{l}\text { We recommend to obtain a repeat blood sample from a reliable site when the lactate value } \\
\text { of a capillary sample is higher than } 3.0 \mathrm{mmol} / \mathrm{L} \text { and to closely follow-up patients and intensify } \\
\text { treatment until lactate values at least drop below } 3.0 \mathrm{mmol} / \mathrm{L} \text {, especially if other concerns } \\
\text { regarding tissue hypoxia are present. }\end{array}$ & Strong agreement \\
\hline 2. & $\begin{array}{l}\text { We recommend to interpret lactate levels always in conjunction with clinical indicators of } \\
\text { poor systemic perfusion and monitoring parameters. }\end{array}$ & Strong agreement \\
\hline \multicolumn{3}{|c|}{ Near infrared spectroscopy } \\
\hline 3. & $\begin{array}{l}\text { Trend in NIRS values may provide valuable physiological information in children with } \\
\text { hemodynamic instability but routine use in all children with hemodynamic instability } \\
\text { is not recommended. }\end{array}$ & Strong agreement \\
\hline 4. & $\begin{array}{l}\text { Near infrared spectroscopy (NIRS) can be useful during the peri-operative period after surgery } \\
\text { for congenital heart defects; however, we recommend against the routine use of NIRS during } \\
\text { non-cardiac surgery. }\end{array}$ & Weak agreement \\
\hline \multicolumn{3}{|c|}{ Microcirculation } \\
\hline 5. & $\begin{array}{l}\text { Many routinely used parameters like capillary refill, peripheral temperature, lactate, NIRS etc., } \\
\text { reflect aspects of the hemodynamic condition, but they do not adequately reflect the } \\
\text { microcirculation. Although central venous to arterial } \mathrm{CO}_{2} \text { difference could provide additional } \\
\text { insight into the microcirculatory condition, we recommend against its use to guide resuscitation } \\
\text { in critically ill children }\end{array}$ & Strong agreement \\
\hline 6. & $\begin{array}{l}\text { We recommend against routine microcirculation evaluation by video microscopy in stable children } \\
\text { except those in clinical studies }\end{array}$ & Strong agreement \\
\hline
\end{tabular}


and lactate may reflect aspects of the hemodynamic condition but do not adequately reflect the microcirculation and cannot be used as such. Although central venous to arterial $\mathrm{CO}_{2}$ difference could provide additional insight into the microcirculatory condition, we currently recommend against its use to guide resuscitation in critically ill children.

\section{Limitations}

We acknowledge the limitations of these recommendations as follows: (1) The most important limitation is the lack of high-quality evidence. These recommendations are based upon expert consensus and review of the published literature including experts' opinions, which can involve subjective value judgments; (2) both lower and upper limits of age, from term infant $>37$ weeks and postnatal age $>4$ weeks to 18 years, are artificial-to avoid overlapping with neonatal and adult populationspecific guidelines; and (3) some of these recommendations may not be appropriate for low-resource settings and may not be applicable in all settings requiring hemodynamic monitoring in children because of their limited availability or expertise.

Nevertheless, despite these limitations, the committee members believe that these are consensual expert recommendations based upon literature review and rigorous standardized process of developing expert consensusfollowed the DELPHI approach, a well-established standardized approach (DELPHI approach) - to reach consensus in such circumstances of limited published evidence to develop evidence-based guidelines.

\section{Future directions}

The committee recognizes that there is an important lack of knowledge and evidence concerning hemodynamic monitoring in children. There is a great need for (1) studying the relationship between measured parameters and end-organ perfusion, and (2) evaluating the clinical efficiency and patient outcome when therapy is guided by specific monitoring technologies.

\section{Conclusions}

Cardiovascular instability is common in children admitted to pediatric intensive care. Multiple-organ dysfunction is commonly associated with cardiovascular derangements in patients with shock and carries high mortality. Effective hemodynamic monitoring can help in identifying cardiovascular instability early and choosing the appropriate targeted therapy timely. Currently, with the exception of management of shock, there are no published HD monitoring guidelines for critically ill children, and the published evidence remains scarce. These are therefore the first expert consensus recommendations for HD monitoring in critically ill children with hemodynamic instability. These recommendations can help clinicians in their clinical practice and may become the frame for future research aiming at providing strong data for evidence-based guidelines in this field.

\section{Supplementary information}

Supplementary information accompanies this paper at https://doi.org/10. 1186/s13054-020-03326-2.

\section{Additional file 1: Table 1 Summary of expert-consensus}

recommendations for hemodynamic monitoring in critically ill neonates and children. Supplementary information. Supplement documents providing background information for the 12 defined subjects.

\section{Acknowledgements}

The authors acknowledge ESPNIC help in providing room and facilities for the panel meetings and anonymous voting for the consensus development.

Take-home message

Cardiovascular instability is common in children admitted to pediatric intensive care units. There are no published guidelines for hemodynamic monitoring (HD) in pediatrics, and there is limited evidence to develop evidence-based HD monitoring guidelines. Besides septic shock quidelines, these are the first expert consensus recommendations driven by a limited acumen of evidence for use in critically ill children with hemodynamic instability to guide clinicians in their clinical practice.

\section{Tweet}

Recommendations for hemodynamic monitoring for critically ill children in pediatric intensive care units: @ESPNIC_society consensus based statement.

\section{Authors' contributions}

$J, Y S$, and $J U$ conceptualized and designed the development of the whole project. $J$ took care of the whole methodology and supervised the whole project. YS and JU wrote the first manuscript draft. All authors performed literature search and analysis, interpreted the literature data with their specific expertise, participated in meeting discussions, and voted on recommendations and manuscript preparation. Moreover, all authors critically reviewed the manuscript for important intellectual content, approved it in its final version, and agreed to be accountable for all aspects of the work. The participation to the project did not entail any honorarium.

Funding

None

Availability of data and materials

Supplementary material provided and attached with manuscript submission. supporting data on consensus development and voting available if required.

Ethics approval and consent to participate

Not applicable. All authors participated by accepting the invitation.

\section{Consent for publication}

Not applicable. All authors have reviewed and agreed on the final manuscript for publication.

\section{Competing interests}

The authors declare no conflict of interest or competing interests.

\section{Author details}

${ }^{1}$ Department of Pediatrics - Neonatology and Pediatric Cardiology, Cambridge University Hospitals and University of Cambridge School of Clinical Medicine, Biomedical Campus, Hills Road, Cambridge CB2 OQQ, UK. ${ }^{2}$ Department of Pediatric Intensive Care, Gregorio Marañón Hospital University Hospital, Madrid, Spain. ${ }^{3}$ Department of Pediatrics, Children's Hospital Colorado, Section of Cardiac Intensive Care, The Heart Institute, Pittsburgh, USA. ${ }^{4}$ Department of Pediatric Intensive Care, Evelina London Children's Hospital, London, UK. ${ }^{5}$ Department of Pediatric Intensive Care, 
Ospedale Pediatrico Bambino Gesù-IRCC, Rome, Italy. ${ }^{6}$ Department of Pediatric and Cardiac Intensive Care, Great Ormond Street Hospital for Children and UCL Institute for Child Health, London, UK. ${ }^{7}$ Department of Pediatric Intensive Care, The Newcastle Upon Tyne Hospitals NHS Foundation Trust, Newcastle, UK. ${ }^{8}$ Department of Neonatology, Radboud University Medical Center, Radboud Institute for Health Sciences, Amalia Children's Hospital, Nijmegen, The Netherlands. ${ }^{9}$ Department of Intensive Care Medicine, Radboud University Medical center, Radboud Institute for Health Sciences, Nijmegen, The Netherlands.

\section{Received: 6 August 2020 Accepted: 5 October 2020} Published online: 22 October 2020

\section{References}

1. Antonelli M, Levy M, Andrews PJ, Chastre J, Hudson LD, Manthous C, et al. Hemodynamic monitoring in shock and implications for management. International Consensus Conference, Paris, France, 27-28 April 2006 Intensive Care Med. 2007;33:575-590. doi: https://doi.org/10.1007/s00134-007-0531-4.

2. Watson RS, Crow SS, Hartman ME, Lacroix J, Odetola FO. Epidemiology and outcomes of pediatric multiple organ dysfunction syndrome. Pediatr Crit Care Med. 2017;18:S4-S16. https://doi.org/10.1097/PCC.0000000000001047.

3. Weiss SL, Fitzgerald JC, Pappachan J, Wheeler D, Jaramillo-Bustamante JC, Salloo A, et al. Sepsis Prevalence Outcomes and Therapies (SPROUT) Study Investigators and Pediatric Acute Lung Injury and Sepsis Investigators (PALI SI) Network. Global epidemiology of pediatric severe sepsis: the sepsis prevalence, outcomes, and therapies study. Am J Respir Crit Care Med. 2015;191:1147-57. https://doi.org/10.1164/rccm.201412-23230C.

4. Weiss SL, Peters MJ, Alhzanni W, D Agus MS, Flori HR, Inwald DP, et al. Surviving sepsis campaign international guidelines for the management of septic shock and sepsis-associated organ dysfunction in children. Pediatr Crit Care Med. 2020;21:e52-e106. https://doi.org/10.1097/PCC.0000000000002198.

5. Davis AL, Carcillo JA, Aneja RK, Deymann AJ, Lin JC, Nguyen TC, et al. American College of Critical Care Medicine Clinical Practice parameters for hemodynamic support of pediatric and neonatal septic shock. Crit Care Med. 2017;45:1061-93. https://doi.org/10.1097/CCM.0000000000002425.

6. Sethi SK, Raghunathan V, Shah S, Dhaliwal M, Jha P, Kumar M, et al. Fluid overload and renal angina index at admission are associated with worse outcomes in critically ill children. Front Pediatr. 2018;6:118. https://doi.org/ 10.3389/fped.2018.00118.

7. Selewski DT, Askenazi DJ, Bridges BC, Cooper DS, Fleming GM, Paden ML, et al. The impact of fluid overload on outcomes in children treated with extracorporeal membrane oxygenation: a multicenter retrospective cohort study. Pediatr Crit Care Med. 2017;18:1126-35. https://doi.org/10.1097/PCC. 0000000000001349.

8. Sivarajan VB, Bohn D. Monitoring of standard hemodynamic parameters: heart rate, systemic blood pressure, atrial pressure, pulse oximetry, and endtidal $\mathrm{CO}_{2}$. Pediatr Crit Care Med. 2011;12:S2-S11. https://doi.org/10.1097/ PCC.0b013e318220e7ea.

9. Kneyber M, de Luca D, Calderini E, Jarreau PH, Javouhey E, Lopez-Herce J, et al. Section Respiratory Failure of the European Society for Paediatric and Neonatal Intensive Care. Recommendations for mechanical ventilation of critically ill children from the Paediatric Mechanical Ventilation Consensus Conference (PEMVECC). Intensive Care Med. 2017;43:1764-80. https://doi. org/10.1007/s00134-017-4920-z.

10. Singh Y, Tissot C, Fraga MV, Yousef N, Cortes RG, Lopez J, et al. International evidence-based guidelines on Point of Care Ultrasound (POCUS) for critically ill neonates and children issued by the POCUS Working Group of the European Society of Paediatric and Neonatal Intensive Care (ESPNIC). Crit Care. 2020;24:65. https://doi.org/10.1186/s13054-020-2787-9.

11. Tume LN, Valla FV, Joosten $K$, Jotterand Chaparro C, Latten L, et al. Nutritional support for children during critical illness: European Society of Pediatric and Neonatal Intensive Care (ESPNIC) metabolism, endocrine and nutrition section position statement and clinical recommendations. Intensive Care Med. 2020;46:411-25. https://doi.org/10.1007/s00134-01905922-5.

12. Atkins D, Best D, Briss PA, Eccles M, Falck-Ytter Y, Flottorp S, et al. Grading quality of evidence and strength of recommendations. BMJ. 2004;328:1490. https://doi.org/10.1136/bmj.328.7454.1490.

13. Brouwers MC, Kerkvliet K, Spithoff K, AGREE Next Steps Consortium. The AGREE Reporting Checklist: a tool to improve reporting of clinical practice guidelines. BMJ. 2016;352:11152. https://doi.org/10.1136/bmj.i1152.
14. Tibby SM, Hatherill M, Marsh MJ, Murdoch IA. Clinicians' abilities to estimate cardiac index in ventilated children and infants. Arch Dis Child. 1997;7:5168. https://doi.org/10.1136/adc.77.6.516.

15. Thompson M, Coad N, Harnden A, Mayon-White R, Perera R, Mant D. How well do vital signs identify children with serious infections in pediatric emergency care? Arch Dis Child. 2009;94:888-93. https://doi.org/10.1136/ adc.2009.159095.

16. Erdem Ö, Kuiper JW, Tibboel D. Hemodynamic coherence in critically ill pediatric patients. Best Pract Res Clin Anaesthesiol. 2016;30:499-510. https:// doi.org/10.1016/j.bpa.2016.10.2002.

17. Matettore A, Ray S, Harrison DA, Brick T, Macrae D, Peters MJ, Inwald DP. Intensive Care Med. 2019;45:1482-3. https://doi.org/10.1007/s00134-01905638-6.

18. Gupta P, Dimple G. Blood pressure measurement in children: where do we stand? Indian Pediatr. 2018;55:289-91.

19. Ray S, Rogers L, Noren DP, Dhar R, Nadel S, Peters MJ, Inwald DP. Risk of over-diagnosis of hypotension in children: a comparative analysis of over 50,000 blood pressure measurements. Intensive Care Med. 2017;43:1540-1. https://doi.org/10.1007/s00134-017-4843-8.

20. Michard F, Sessler DI, Saugel B. Non-invasive arterial pressure monitoring revisited. Intensive Care Med. 2018;44:2213-5. https://doi.org/10.1007/ s00134-018-5108-x.

21. Jansen TC, van Bommel J, Schoonderbeek FJ, et al. Early lactate-guided therapy in intensive care unit patients: a multicenter, open-label, randomized controlled trial. Am J Respir Crit Care Med. 2010;182:752-61. https://doi.org/10.1164/rccm.200912-19180C.

22. Eytan D, Goodwin AJ, Greer R, Guerguerian AM, Mazwi M, Laussen PC. Distributions and behavior of vital signs in critically ill children by admission diagnosis. Pediatr Crit Care Med. 2018;19:115-24. https://doi.org/10.1097/ PCC.0000000000001395.

23. Eytan D, Goodwin AJ, Greer R, Guerguerian AM, Laussen PC. Heart rate and blood pressure centile curves and distributions by age of hospitalized critically ill children. Front Pediatr. 2017;5:52. https://doi.org/10.3389/fped.2017.00052.

24. Banker A, Bell C, Gupta-Malhotra M, Samuels J. Blood pressure percentile charts to identify high or low blood pressure in children. BMC Pediatr. 2016; 16, 98. https://doi.org/10.1186/s12887-016-0633-7.

25. Stergiou GS, Boubouchairopoulou N, Kollias A. Accuracy of automated blood pressure measurement in children: evidence, issues, and perspectives. Hypertension. 2017;69:1000-6. https://doi.org/10.1161/HYPERTENSIONAHA. 116.08553 .

26. Mark JB. Central venous pressure monitoring: clinical insights beyond the numbers. J Cardiothorac Vasc Anesth. 1991;5:163-73. https://doi.org/10. 1016/1053-0770(91)90333-0.

27. Magder S, Bafaqeeh F. The clinical role of central venous pressure measurements. J Intensive Care Med. 2007;22:44-51. https://doi.org/10.1177/ 0885066606295303.

28. Stricker PA, Lin EE, Fiadjoe JE, et al. Evaluation of central venous pressure monitoring in children undergoing craniofacial reconstruction surgery. Anesth Analg. 2013;116:411-9. https://doi.org/10.1213/ANE. 0b013e31827008e6.

29. Gan H, Cannesson M, Chandler JR, Ansermino JM. Predicting fluid responsiveness in children: a systematic review. Anesth Analg. 2013;117: 1380-92. https://doi.org/10.1213/ANE.0b013e3182a9557e.

30. Renner J, Broch O, Duetschke P, Scheewe J, Höcker J, Moseby M, Jung O, Bein B. Prediction of fluid responsiveness in infants and neonates undergoing congenital heart surgery. Br J Anaesth. 2012;108:108-15. https:// doi.org/10.1093/bja/aer371.

31. Marik PE, Cavallazzi R. Does the central venous pressure predict fluid responsiveness? An updated meta-analysis and a plea for some common sense. Crit Care Med. 2013;41:1774-81. https://doi.org/10.1097/CCM. Ob013e31828a25fd.

32. Kumar A, Anel R, Bunnell E, Habet K, Zanotti S, Marshall S, et al. Pulmonary artery occlusion pressure and central venous pressure fail to predict ventricular filling volume, cardiac performance, or the response to volume infusion in normal subjects. Crit Care Med. 2004;32:691-9. https://doi.org/10. 1097/01.ccm.0000114996.68110.c9.

33. Bronicki RA. Venous oximetry and the assessment of oxygen transport balance. Pediatr Crit Care Med. 2011;12:S21-6. https://doi.org/10.1097/PCC. Ob013e3182211667.

34. Pérez AC, Eulmesekian PG, Minces PG, Schnitzler EJ. Adequate agreement between venous oxygen saturation in right atrium and pulmonary artery in 
critically ill children. Pediatr Crit Care Med. 2009;10:76-9. https://doi.org/10 1097/PCC.0b013e318193699d.

35. Tibby SM, Murdoch IA. Monitoring cardiac function in intensive care. Arch Dis Child. 2003;88:46-52. https://doi.org/10.1136/adc.88.1.46.

36. de Oliveira CF, de Oliveira DS, Gottschald AF, Moura JD, Costa GA, Ventura AC, et al. ACCM/PALS haemodynamic support guidelines for pediatric septic shock: an outcomes comparison with and without monitoring central venous oxygen saturation. Intensive Care Med. 2008;34:1065-75. https://doi. org/10.1007/s00134-008-1085-9.

37. Arikan AA, Zappitelli M, Goldstein SL, Naipaul A, Jefferson LS, Loftis LL. Fluid overload is associated with impaired oxygenation and morbidity in critically ill children. Pediatr Crit Care Med. 2012;13:253-8. https://doi.org/10.1097/ PCC.0b013e31822882a3.

38. Wang $X$, Jiang L, Liu S, Ge Y, Gao J. Value of respiratory variation of aortic peak velocity in predicting children receiving mechanical ventilation: a systematic review and meta-analysis. Crit Care. 2019;23:372. doi: https://doi. org/10.1186/s13054-019-2647-7.

39. Lee JH, Kim EH, Jang YE, Kim HS, Kim JT. Fluid responsiveness in the pediatric population. Korean J Anesthesiol. 2019;72:429-40. https://doi.org/ 10.4097/kja.19305.

40. Singh Y. Echocardiographic evaluation of hemodynamics in neonates and children. Front Pediatr. 2017;5:201. https://doi.org/10.3389/fped.2017.00201.

41. Fraga MV, Stoller JZ, Glau CL, De Luca D, Rempell RG, Wenger JL, et al. Seeing is believing: ultrasound in pediatric procedural performance. Pediatrics. 2019;144:e20191401. https://doi.org/10.1542/peds.2019-1401.

42. Pereira de Souza Neto E, Grousson S, Duflo F, Ducreux C, Joly H, Convert J, et al. Predicting fluid responsiveness in mechanically ventilated children under general anaesthesia using dynamic parameters and transthoracic echocardiography. Br J Anaesth. 2011;106:856-64. https://doi.org/10.1093/bja/aer090.

43. de Boode WP, van der Lee R, Horsberg Eriksen B, Nestaas E, Dempsey E, Singh $Y$, et al. European Special Interest Group Neonatologist Performed Echocardiography' (NPE). The role of Neonatologist Performed Echocardiography in the assessment and management of neonatal shock. Pediatr Res. 2018;84:57-67. https://doi.org/10.1038/s41390-018-0081-1.

44. ProulX F, Lemson J, Choker G, Tibby SM. Hemodynamic monitoring by transpulmonary thermodilution and pulse contour analysis in critically ill children. Pediatr Crit Care Med. 2011;12:459-66. https://doi.org/10.1097/PCC. 0b013e3182070959.

45. Nusmeier A, van der Hoeven JG, Lemson J. Cardiac output monitoring in pediatric patients. Expert Rev Med Devices. 2010;7:503-17. https://doi.org/ 10.1586/erd.10.19.

46. Wurzer P, Branski LK, Jeschke MG, Ali A, Kinsky MP, Bohanon FJ, et al. Transpulmonary thermodilution versus transthoracic echocardiography for cardiac output measurements in severely burned children. Shock. 2016;46: 249-53. https://doi.org/10.1097/SHK.0000000000000627.

47. Singh $Y$, Katheria AC, Vora F. Advances in diagnosis and management of hemodynamic instability in neonatal shock. Front Pediatr. 2018;6:2. https:/ doi.org/10.3389/fped.2018.00002.

48. Lindberg L, Johansson S, Perez-de-Sa V. Validation of an ultrasound dilution technology for cardiac output measurement and shunt detection in infants and children. Pediatr Crit Care Med. 2014;15:139-47. https://doi.org/10.1097/ PCC.0000000000000053.

49. Suehiro K, Joosten A, Murphy LS, Desebbe O, Alexander B, Kim SH, Cannesson M. Accuracy and precision of minimally-invasive cardiac output monitoring in children: a systematic review and meta-analysis. J Clin Monit Comput. 2016;30:603-20. https://doi.org/10.1007/s10877-015-9757-9.

50. Perkin RM, Anas N. Pulmonary artery catheters. Pediatr Crit Care Med. 2011; 12:S12-20. https://doi.org/10.1097/PCC.0b013e318220f079.

51. Humphrey CB, Gibbons JA, Folkerth TL, Shapiro AR, Fosburg RG. An analysis of direct and indirect measurements of left atrial filling pressure. J Thorac Cardiovasc Surg. 1976;71:643-7.

52. Flori HR, Johnson LD, Hanley FL, Fineman JR. Transthoracic intracardiac catheters in pediatric patients recovering from congenital heart defect surgery: associated complications and outcomes. Crit Care Med. 2000;28: 2997-3001. https://doi.org/10.1097/00003246-200008000-00053.

53. Figueras-Coll M, Sanchez-de-Toledo J, Gran F, Abella R, Perez-Hoyos S, Rosés F. Echocardiography in the assessment of left atrial pressure after pediatric heart surgery: a comparison study with measurements obtained from left atrial catheter. World J Pediatr Congenit Heart Surg. 2015;6:438-42. https:// doi.org/10.1177/2150135115589999
54. Goldberg DJ, Quartermain MD, Glatz AC, Hall EK, Davis E, Kren SA, et al. Doppler tissue imaging in children following cardiac transplantation: a comparison to catheter derived hemodynamics. Pediatr Transplant. 2011;15: 488-94. https://doi.org/10.1111/j.1399-3046.2011.01503.x.

55. Moceri P, Baudouy D, Chiche O, Cerboni P, Bouvier P, Chaussade C, Ferrari E. Imaging in pulmonary hypertension: focus on the role of echocardiography. Arch Cardiovasc Dis. 2014;107:261-71. https://doi.org/10.1016/j.acvd.2014.02. 005.

56. Jansen TC, van Bommel J, Schoonderbeek FJ, Sleeswijk Visser SJ, van der Klooster JM, Lima AP, et al. LACTATE study group. Early lactate-guided therapy in intensive care unit patients: a multicenter, open-label, randomized controlled trial. Am J Respir Crit Care Med. 2010;182:752-61. https://doi.org/10.1164/rccm.200912-19180C.

57. Gallagher EJ, Rodriguez K, Touger M. Agreement between peripheral venous and arterial lactate levels. Ann Emerg Med. 1997;29:479-83.

58. Samaraweera SA, Gibbons B, Gour A, Sedgwick P. Arterial versus venous lactate: a measure of sepsis in children. Eur J Pediatr. 2017;176:1055-60. https://doi.org/10.1007/s00431-017-2925-9.

59. Stoll D, Englund E, Hillborg H, Vedin S, Larsson A. Capillary and venous lactate measurements with a handheld device compared to venous bloodgas analysis for emergency patients. Scand J Trauma Resusc Emerg Med. 2018;26:47. https://doi.org/10.1186/s13049-018-0510-5.

60. Kumar R, Kumar N. Validation of lactate clearance at $6 \mathrm{~h}$ for mortality prediction in critically ill children. Indian J Crit Care Med. 2016;20:570-4. https://doi.org/10.4103/0972-5229.192040.

61. Hatherill M, Mclntyre AG, Wattie M, Murdoch IA. Early hyperlactataemia in critically ill children. Intensive Care Med. 2000;26:314-8. https://doi.org/10. 1007/s001340051155.

62. Allen M. Lactate and acid base as a hemodynamic monitor and markers of cellular perfusion. Pediatr Crit Care Med. 2011;12:S43-9. https://doi.org/10. 1097/PCC.0b013e3182211aed.

63. Tina LG, Frigiola A, Abella R, Artale B, Puleo G, D'Angelo S, et al. Near Infrared Spectroscopy in healthy preterm and term newborns: correlation with gestational age and standard monitoring parameters. Curr Neurovasc Res. 2009;6:148-54. https://doi.org/10.2174/156720209788970090.

64. Bernal NP, Hoffman GM, Ghanayem NS, Arca MJ. Cerebral and somatic nearinfrared spectroscopy in normal newborns. J Pediatr Surg. 2010;45:1306-10. https://doi.org/10.1016/j.jpedsurg.2010.02.110.

65. Johnson BA, Hoffman GM, Tweddell JS, Cava JR, Basir M, Mitchell ME, et al. Near-infrared spectroscopy in neonates before palliation of hypoplastic left heart syndrome. Ann Thorac Surg. 2009;87:571-7. https://doi.org/10.1016/j. athoracsur.2008.10.043

66. Kurth CD, Steven JL, Montenegro LM, Watzman HM, Gaynor JW, Spray TL, Nicolson SC. Cerebral oxygen saturation before congenital heart surgery. Ann Thorac Surg. 2001;72:187-92. https://doi.org/10.1016/s00034975(01)02632-7.

67. Fenton KN, Freeman K, Glogowski K, Fogg S, Duncan KF. The significance of baseline cerebral oxygen saturation in children undergoing congenital heart surgery. Am J Surg. 2005;190:260-3. https://doi.org/10.1016/j.amjsurg.2005.05.023.

68. Schmidt $C$, Heringlake $M$, Kellner $P$, Berggreen AE, Maurer $H$, Brandt $S$, et al. The effects of systemic oxygenation on cerebral oxygen saturation and its relationship to mixed venous oxygen saturation: a prospective observational study comparison of the INVOS and ForeSight Elite cerebral oximeters. Can J Anaesth. 2018;65:766-75. https://doi.org/10.1007/s12630-018-1093-3.

69. Dabal RJ, Rhodes LA, Borasino S, Law MA, Robert SM, Alten JA. Inferior vena cava oxygen saturation monitoring after the Norwood procedure. Ann Thorac Surg. 2013;95:2114-20. https://doi.org/10.1016/j.athoracsur.2013.01.076.

70. Hoffman GM, Ghanayem NS, Tweddell JS. Noninvasive assessment of cardiac output. Semin Thorac Cardiovasc Surg Pediatr Card Surg Annu. 2005:12-21. https://doi.org/10.1053/j.pcsu.2005.01.005.

71. Massey MJ, Larochelle E, Najarro G, Karmacharla A, Arnold R, Trzeciak S, et al. The microcirculation image quality score: development and preliminary evaluation of a proposed approach to grading quality of image acquisition for bedside videomicroscopy. J Crit Care. 2013;28:913-7. https://doi.org/10. 1016/j.jcrc.2013.06.015.

72. Top AP, van Dijk M, van Velzen JE, Ince C, Tibboel D. Functional capillary density decreases after the first week of life in term neonates. Neonatology. 9. 2011;9:73-7. https://doi.org/10.1159/000316945.

73. González R, López J, Urbano J, Solana MJ, Fernández SN, Santiago MJ, López-Herce J. Evaluation of sublingual microcirculation in a pediatric 
intensive care unit: prospective observational study about its feasibility and utility. BMC Pediatr. 2017;17:75. https://doi.org/10.1186/s12887-017-0837-5.

74. Top AP, Ince C, de Meij N, van Dijk M, Tibboel D. Persistent low microcirculatory vessel density in nonsurvivors of sepsis in pediatric intensive care. Crit Care Med. 2011;39:8-13. https://doi.org/10.1097/CCM. Ob013e3181fb7994.

75. Scolletta S, Marianello D, Isgrò G, Dapoto A, Terranova V, Franchi F, et al. Microcirculatory changes in children undergoing cardiac surgery: a prospective observational study. Br J Anaesth. 2016;117:206-13. https://doi. org/10.1093/bja/aew187.

76. Schinagl CM, Mormanova ZH, Puchwein-Schwepcke A, Schmid I, GenzelBoroviczény $\mathrm{O}$. The effect of red blood cell transfusion on the microcirculation of anemic children. Eur J Pediatr. 2016;175:793-8. https:/ doi.org/10.1007/s00431-016-2704-Z.

77. Paize F, Sarginson R, Makwana N, Baines PB, Thomson AP, Sinha I, et al. Changes in the sublingual microcirculation and endothelial adhesion molecules during the course of severe meningococcal disease treated in the pediatric intensive care unit. Intensive Care Med. 2012;38:863-71. https://doi.org/10.1007/s00134-012-2476-5

\section{Publisher's Note}

Springer Nature remains neutral with regard to jurisdictional claims in published maps and institutional affiliations.

Ready to submit your research? Choose BMC and benefit from:

- fast, convenient online submission

- thorough peer review by experienced researchers in your field

- rapid publication on acceptance

- support for research data, including large and complex data types

- gold Open Access which fosters wider collaboration and increased citations

- maximum visibility for your research: over $100 \mathrm{M}$ website views per year

At $\mathrm{BMC}$, research is always in progress.

Learn more biomedcentral.com/submissions 